\title{
Acceptability and feasibility of a 12-week yoga vs. educational film program for the management of restless legs syndrome (RLS): study protocol for a randomized controlled trial
}

\author{
Terry Kit Selfe ${ }^{1 *}$, Sijin Wen ${ }^{2}$, Karen Sherman ${ }^{3}$, Maryanna Klatt ${ }^{4}$ and Kim E. Innes ${ }^{5}$
}

\begin{abstract}
Background: Restless legs syndrome (RLS) is a common and burdensome sleep disorder associated with profound impairment of health, well-being, and quality of life. Unfortunately, the medications used for RLS management carry risk of serious side effects, including augmentation of symptoms. Yoga, an ancient mind-body discipline designed to promote physical, emotional, and mental well-being, may offer a viable, low-risk new treatment. The primary objectives of this pilot, parallel-arm, randomized controlled trial (RCT) are to assess the acceptability and feasibility of a 12-week yoga vs. educational film program for the management of RLS.
\end{abstract}

Methods: Forty-four adults with confirmed moderate to severe RLS will be recruited and randomized to a 12-week yoga $(n=22)$ or standardized educational film program $(N=22)$. Yoga group participants will attend two 75 -min lyengar yoga classes per week for the first 4 weeks, then one 75-min class per week for the remaining 8 weeks, and will complete a 30-min homework routine on non-class days. Educational film group participants will attend one 75-min class per week for 12 weeks and complete a daily RLS treatment log; classes will include information on: RLS management, including sleep hygiene practices; other sleep disorders; and complementary therapies likely to be of interest to those participating in a yoga and sleep education study.

Yoga and treatment logs will be collected weekly. Feasibility outcomes will include recruitment, enrollment, and randomization rates, retention, adherence, and program satisfaction. Program evaluation and yoga-dosing questionnaires will be collected at week 12; data on exploratory outcomes (e.g., RLS symptom severity (IRLS), sleep quality (PSQI), mood (POMS, PSS), and health-related quality of life (SF-36)) will be gathered at baseline and week 12.

Discussion: This study will lay the essential groundwork for a planned larger RCT to determine the efficacy of a yoga program for reducing symptoms and associated burden of RLS. If the findings of the current trial and the subsequent larger RCTs are positive, this study will also help support a new approach to clinical treatment of this challenging disorder, help foster improved understanding of RLS etiology, and ultimately contribute to reducing the individual, societal, and economic burden associated with this condition.

Trial registration: ClinicalTrials.gov, ID: NCT03570515. Retrospectively registered on 1 February 2017.

Keywords: Restless legs syndrome, Yoga, Mind-body therapy, Behavioral intervention, Feasibility, Acceptability, Sleep, Mood, Quality of life

\footnotetext{
* Correspondence: tselfe1@ufl.edu

${ }^{1}$ Health Science Center Libraries, University of Florida, PO Box 100206,

Gainesville, FL 32610, USA

Full list of author information is available at the end of the article
}

(c) The Author(s). 2019 Open Access This article is distributed under the terms of the Creative Commons Attribution 4.0 International License (http://creativecommons.org/licenses/by/4.0/), which permits unrestricted use, distribution, and reproduction in any medium, provided you give appropriate credit to the original author(s) and the source, provide a link to the Creative Commons license, and indicate if changes were made. The Creative Commons Public Domain Dedication waiver (http://creativecommons.org/publicdomain/zero/1.0/) applies to the data made available in this article, unless otherwise stated. 


\section{Background}

Restless legs syndrome (RLS) is a distressing sleep and sensorimotor disorder characterized by a compelling urge to move the legs, which is usually accompanied by unpleasant sensations in the legs that begins or worsens during periods of inactivity, is worse at night, and is at least partially relieved by movement [1]. As detailed in our recent reviews [2, 3], RLS affects up to $29 \%$ of US and European adults, with estimated prevalence rates averaging $12 \%$ in the general population, and $19.5 \%$ in primary care patients [3]. Up to $65 \%$ or more of those affected suffer moderate to severe symptoms [3]. While increasingly recognized as a disorder of significant clinical and economic import [3-7], the etiology of RLS remains poorly understood [8-10]. Currently, the primary underlying causes of RLS are thought to be genetic predisposition, dopaminergic dysfunction, and deficiencies in iron metabolism [814 ], although these factors have to date offered only a partial explanation [2]. As discussed in our recent papers [2, $3,15]$, emerging evidence suggests that autonomic and hypothalamic-pituitary-adrenal (HPA) axis dysregulation may also play an important role in RLS pathogenesis and progression.

RLS is associated with significant sleep disturbance [6, 16 , 17], the most common presenting complaint of those seeking medical care for RLS [18, 19], and is a major cause of chronic sleep loss [20]. Recent studies suggest that up to $40 \%$ of those with insomnia suffer from RLS [21, 22]. Likewise, mood disturbance is common in those affected by RLS [16, 23], and can both result from, and contribute to, sleep deficits [24]. Recent community-based studies suggest that RLS may also be linked, in a bidirectional manner, to cardiovascular disease (CVD), stroke, and key components of the metabolic syndrome [2, 8, 9, 25], associations that may be in part mediated by RLS's adverse effects on sleep and mood [26, 27]. RLS leads to significant impairment of daily functioning and quality of life, increased health-related costs, and declines in productivity that are comparable to those reported in other serious chronic disorders, including diabetes, hypertension, Parkinson's disease, and stroke [6, 7, 26, 28, 29]. Collectively, these studies suggest that RLS is a serious, chronic condition of major public health import, affecting a large percentage of the adult population and exacting a significant toll in terms of health, quality of life and economic cost.

There is no cure for RLS, with current treatments aimed at symptom management. Pharmaceuticals, notably dopaminergic agents and anti-seizure medications ( $\alpha 2 \delta$ ligands) remain first-line treatments for RLS, with opioids and, less commonly, benzodiazepines, used as second-line therapies [25, 26, 30-32]. Unfortunately, all medications used for RLS management carry risk of serious side effects (with $6-80 \%$ of patients affected, depending on the medication and duration of treatment) $[26,31,33]$. Among the most troubling is augmentation of symptoms, a serious clinical problem which has been reported for all dopaminergic drugs and certain opioids, with risk increasing with longer treatment duration $[25,26,30,31,34]$. For example, in a recent community-based study of 266 RLS patients who had been treated with dopaminergic agents, only $25 \%$ had no evidence of augmentation [35]. Other common side effects include somnolence and general toxicity (all RLS medications); impulse control disorders (dopaminereceptor agonists); dyskinesias (dopaminergic agents), nausea and vomiting (dopaminergic agents, opioids); mood disturbances ( $\alpha 2 \delta$ ligands, opioids, benzodiazepines); weight gain ( $\alpha 2 \delta$ ligands); addiction (opioids, benzodiazepines); increased risk for falls (opioids, benzodiazepines), and other adverse sequelae [25, 26, 30, 31, 34, 36-44]. In addition, these effects can be particularly problematic in older adults $[45,46]$, who suffer disproportionately from RLS [42, 47]. In addition, the efficacy of all RLS medications commonly diminishes with time [31, 48-51], leaving patients with few treatment options. Given these drawbacks, investigation of safe, sustainable, nonpharmacologic therapies, that may not only alleviate RLS symptoms, but address associated comorbidities and apparent risk factors, is clearly warranted.

However, despite current clinical guidelines, including recent recommendations from the International RLS Study Group Task Force that medications be used only to treat "clinically significant symptoms that cannot be effectively managed behaviorally" [31], behavioral treatments remain largely untested and rarely implemented in practice. Specifically, although lifestyle changes and relaxation therapies, including yoga, are recommended for those suffering RLS [10], rigorous supporting research is lacking. To our knowledge, aside from our pilot studies $[15,52]$ only three small published trials have examined the potential benefits of lifestyle/behavioral interventions for individuals with RLS. These include a pre-post trial of cognitive behavioral therapy in 25 adults with primary RLS and psychosocial impairment, and two studies evaluating the effects of a 12-16-week exercise program vs. usual care on RLS symptoms: a non-randomized controlled trial in 14 hemodialysis patients [53] and a randomized controlled trial (RCT) of 23 community-dwelling older adults [54]. All reported significant improvement in RLS symptoms among participants assigned to the active intervention vs. the control group [53, 54] or baseline [55], suggesting that behavioral therapies may benefit those with RLS.

\section{Study rationale}

Supported by our strong preliminary findings, drawing on the strengths of multiple disciplines, and testing a 
novel, clinical treatment paradigm, the proposed study will be the first RCT to rigorously assess the feasibility and acceptability of a promising mind-body therapy (yoga) for alleviating RLS symptoms and symptom burden. The study will provide essential preliminary data for a larger RCT to assess the efficacy of yoga for RLS management, and to evaluate the long-term effects of this novel therapy. Most important, this study will, in providing the foundation for the first rigorous trial of a novel behavioral therapy for RLS, have the potential to significantly alter the clinical management of this common and burdensome disorder.

As detailed above, medications used in RLS management carry risk of serious side effects that are especially problematic for older adults, and are often inappropriate for long-term use. Clearly, there is a need to investigate potentially safer, sustainable, low-cost therapies that are suitable for long-term use, and that have the potential not only to attenuate RLS symptoms, but to address the common comorbidities that may both result from, and contribute to, RLS. Particularly urgent is the investigation of promising patient-centered therapies that may enable and encourage patients to effectively manage their own health. While current guidelines indicate that behavioral management should comprise first-line treatment for RLS, and yoga and other relaxation therapies are sometimes recommended to RLS patients [56], rigorous supportive research is lacking. Findings from our two small, proof-of-concept studies suggest that yoga may significantly reduce RLS symptoms, improve sleep, and enhance mood, and decrease blood pressure in adults with RLS; observed effect sizes in these small trials were similar or superior to those reported in RLS drug trials [57-63], suggesting that yoga may offer a viable, multi-faceted, low-cost new treatment that is safer and more suitable for long-term use, and that has the potential to address symptoms as well as contributing factors.

An ancient mind-body discipline designed to promote physical, emotional, and mental well-being [64], yoga continues to gain popularity in the US, with over 13 million Americans reporting use of yoga in 2007 [65]. Our recent exploratory studies suggest that yoga may attenuate RLS symptoms, improve sleep, enhance mood, decrease stress, and reduce sympathetic activation in adults with RLS $[15,66]$, with observed effect sizes similar to, or greater than, those reported in trials of established drug treatments [57-63]. Numerous studies have shown yoga to improve quality of life, enhance well-being, and reduce pain, outcomes of clear relevance to RLS sufferers [67-75]. In addition, evidence from controlled trials by our group and others suggest that yoga may also improve indices of metabolic and autonomic function linked to both RLS and CVD risk [2, 9,
76-80]. Yoga has logistical advantages as well. Typically, a gentle practice with no appreciable side effects, yoga is relatively simple to learn and inexpensive to implement, and can be safely performed by a broad range of populations, including chronically ill, elderly, and even disabled adults [81-86]. The practice of yoga often brings immediate positive benefits, including feelings of relaxation and tranquility, helping to encourage continued adherence [77]. However, despite the promise of yoga as a safe, sustainable, cost-effective treatment for RLS, rigorous controlled studies are lacking.

\section{Design}

This study will be a pilot, parallel-arm, community-based, RCT to assess the feasibility and acceptability of a 12-week yoga program vs. a 12-week educational film program for the management of RLS in adults aged $\geq 18$ years with confirmed moderate to severe RLS. The protocol addresses the elements described in the Standard Protocol Items: Recommendations for Interventional Trials (SPIRIT) checklist (Additional file 1).

\section{Objectives \\ Primary objective}

Our primary goal is to assess the acceptability and feasibility of a 12-week yoga vs. educational film program for RLS management in adults with moderate to severe RLS. Primary aims are as follows:

Aim.1a. Assess participant recruitment and enrollment rates and determine optimal recruitment strategies.

Reasons for refusal will be recorded and the information used to develop and implement strategies to address these barriers where appropriate

Aim.1b. Determine participant retention rates and adherence in the yoga and educational film groups, with $80 \%$ retention, $80 \%$ class attendance, $75 \%$ home practice (yoga group), and $80 \%$ completion of weekly logs serving as benchmarks for acceptability. Information on barriers to adherence will be collected and used to inform ongoing strategies to enhance compliance

\section{Secondary objectives}

Our secondary objectives include the assessment of treatment fidelity in the two programs, as well as participant willingness to enroll in yoga programs of varying duration and intensity. In addition, we will measure RLS symptom severity, sleep quality, mood, and health-related quality of life at baseline and 12 weeks to obtain effect size estimates for these exploratory outcomes. This information will provide critical data on which to base our planned larger RCT to determine the efficacy of yoga as a potential therapy for RLS. Secondary aims are as follows: 
Aim.2.1. Monitor and assess treatment fidelity in the yoga and educational film programs, using specific metrics to gauge fidelity. Lapses in fidelity will be recorded and the data used to inform strategies to address these lapses

Aim.2.2. Assess the effect sizes at week 12 of a beginner yoga and a structured educational film program for RLS symptoms and related key exploratory outcomes (sleep quality, mood, perceived stress, and healthrelated quality of life) in adults with moderate to severe RLS, using well-validated, self-report instruments commonly employed in evaluating RLS treatments. Effect size estimates for these exploratory outcomes will provide critical data on which to base sample sizes in future larger trials, as well as provide important preliminary information on sensitivity of specific endpoints to change with a 12-week yoga intervention Aim.2.3. Determine acceptable doses of yoga for a trial by assessing participant willingness to complete, as well as preference for yoga programs of the following duration and intensity: 8 weeks, 16 classes ( $2 x /$ week); 12 weeks, 16 classes ( $2 x /$ week for first 4 weeks, $1 x$ /week thereafter); 16 weeks, 16 classes (1x/week).

Acceptability and preferences will be evaluated using a self-report questionnaire administered to all participants at the follow-up assessment visit

\section{Methods}

\section{Participants}

Forty-four ambulatory, overall healthy adults aged $\geq 18$ years with confirmed moderate to severe RLS will be recruited and randomized to a 12-week beginner yoga program $(n=22)$ or a standardized 12-week educational film program $(N=22)$, modeled on interventions used in our previous trials $[15,87]$ (see Fig. 1).

\section{Inclusion criteria}

Study participants will be ambulatory adults $\geq 1$ years of age with moderate-severe RLS, defined as:

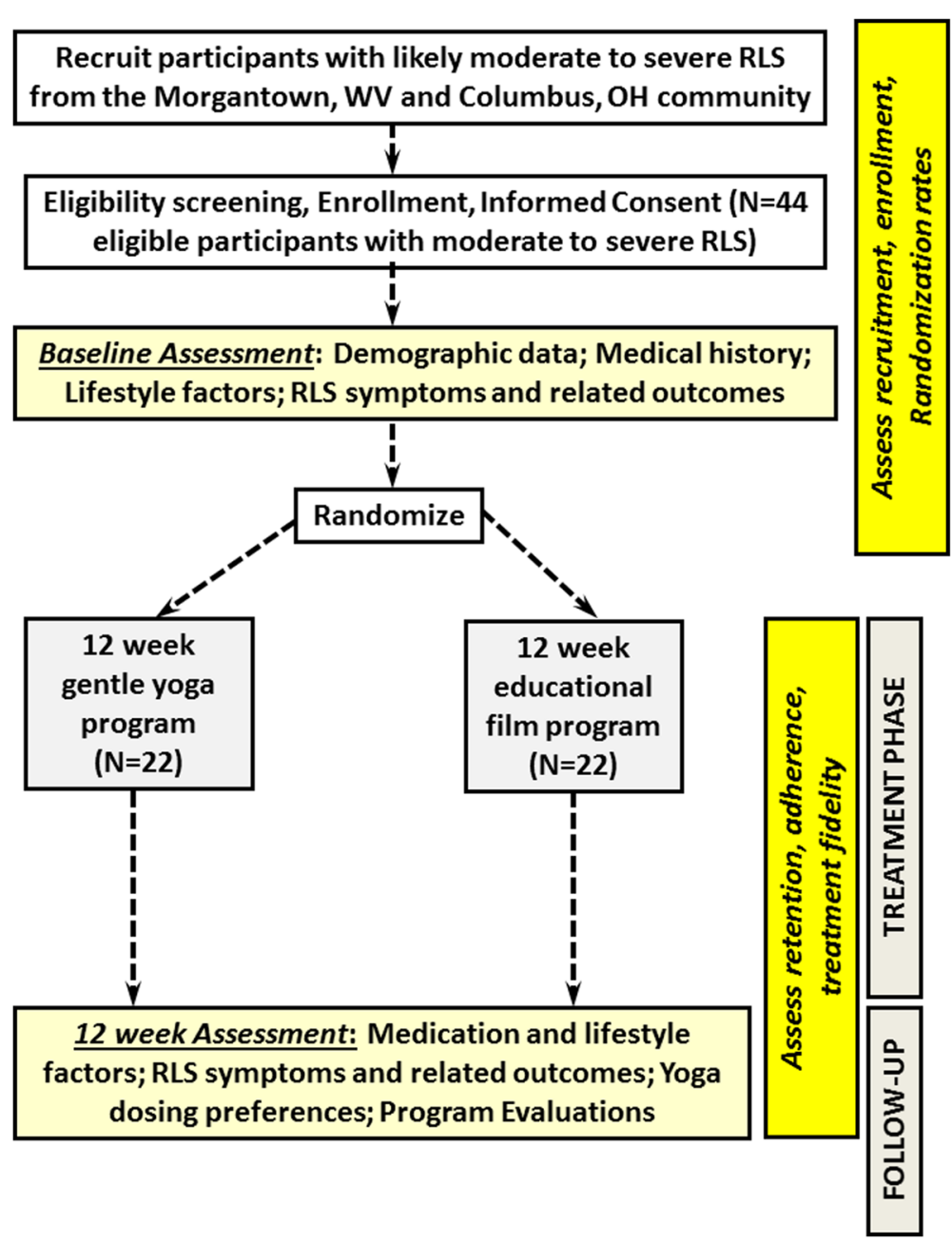

Fig. 1 Study flow diagram 
1. Symptoms that meet all five of the International RLS Study Group's essential diagnostic criteria for RLS [1, 88] (i.e., (1) an urge to move the legs, often associated with discomfort or disagreeable sensations in the legs, that (2) begins or worsen during periods of rest or inactivity; (3) is partially or totally relieved by movement; (4) is worse or only occurs in the evening or night; and (5) is not solely accounted for by another condition (e.g., leg cramps, positional discomfort, habitual foot-tapping))

2. RLS symptoms at least $1 \mathrm{x} /$ week for the previous 3 months

3. A score of at least 2 points (moderate) IRLS question 6: "How severe was your RLS as a whole?" $[89,90]$; and

4. Confirmation of RLS diagnosis and study eligibility by a physician trained in sleep medicine; these criteria will help ensure exclusion of mimics (e.g., leg cramps, positional discomfort, arthritis pain, etc.) $[20,91]$. Additional criteria include: willingness and ability to complete the 12-week yoga or educational film program and all study assessments; and willingness to avoid use of any new drugs or treatments other than the assigned intervention.

\section{Exclusion criteria}

Exclusion criteria are as follows: practiced yoga within the past year; currently on anti-psychotic medication; changed dosage of dopaminergic agents (e.g., levodopa, ropinirole, pramipexole) or any other central nervous system agents (e.g., sedative hypnotics, GABA analogs, narcotic analgesics, antiadrenergic agents, or anticonvulsants) within the past 3 months; hemoglobin $(\mathrm{Hb})<12$ $\mathrm{g} / \mathrm{dL}$ for women, $<13 \mathrm{~g} / \mathrm{dL}$ for men; any orthopedic, neurologic, or other condition that might prevent safe completion of a 12-week yoga program or confound assessments (e.g., neuropathy; Parkinson's disease; stroke; rheumatoid arthritis; renal failure; sleep apnea; recent (within the last 6 months) myocardial infarction; heart failure; cancer (other than non-melanoma skin cancer); pregnancy, or within 6 months post-partum). These medical exclusion criteria are consistent with those commonly employed in trials of RLS drugs and other RLS interventions [54, 92-96].

\section{Sample size}

We performed a simulation study to determine the total sample size required to derive precise estimates of effect sizes for a two-arm randomized trial using a 1:1 randomization scheme for the primary intervention (yoga) and the educational film program; estimates were based on regression models using multiple simulations and scenarios, and specifically accounting for heterogeneity of effects. We considered seven combinations of effect sizes at 23 different sample sizes for total of 161 effect and sample size combinations. For each combination we ran 5000 simulations for a total of 805,500 simulations. The seven effect-size combinations were structured under the conservative assumption that all interventions would lead to a small to moderate improvement in outcomes and that the yoga intervention would lead to an improvement equal to or greater than the comparator condition. We used repeated simulations to determine the required post-attrition total sample size needed to obtain precise estimates of all three treatment effects under an intent-to-treat (ITT) analysis of variance (ANOVA) analysis. Based on findings of the simulation study and assuming 20\% attrition, a sample size of 44 participants will permit reasonably precise estimates (within 95\% confidence intervals of the true effect size value) for the two interventions, as well as reasonable estimates of recruitment, randomization, and adherence rates; moreover, estimates remain robust even at 30\% attrition. Thus, the study will be adequately powered even if effect sizes for the yoga program are substantially smaller, and attrition rates greater than observed in our pilot studies $[15,66]$.

\section{Recruitment and study setting}

Participants will be recruited from two sites: Morgantown, WV metropolitan area (WVU site) and Columbus, Ohio (The Ohio State University (OSU) site). In the WVU site, we will mail recruitment letters to all patients visiting a Morgantown area University Health Associates (UHA) clinic, who received a diagnosis of RLS (ICD-9 code: $333.94,333.99$ ) during the 5 years preceding study onset, as identified by electronic visit data. Consistent with Institutional Review Board (IRB) and Health Insurance Portability and Accountability Act (HIPAA) guidelines, the mailing list was obtained based on IRB approval of a waiver of research participants' authorization for the use/disclosure of information. Only the minimum necessary information needed to identify potentially eligible subjects was accessed (i.e., name and mailing address). At both sites, we are recruiting from the community using local television, radio, and print media advertisements, as well as flyers and brochures posted in public places such as community bulletin boards (physical and electronic); health center waiting areas, and intranets. Study staff will also give presentations regarding the trial to interested lay and professional groups in the area, including clinician, support, university extension, and church groups, as well as other regional organizations and conferences. These strategies have proved effective in recruiting participants for previous studies of yoga-based interventions by WVU investigators in Morgantown, WV and by our partner investigators at OSU in Columbus, $\mathrm{OH}[52,97-102]$. 
Prospective study participants are being invited to contact the WVU study coordinator for further information. A member of the investigative team will describe the study, including eligibility criteria, to each potential participant over the telephone; those still interested will then be scheduled for a screening interview and baseline assessment, and sent a copy of the consent form to preview at their leisure prior to their first appointment.

\section{Consent and screening}

We plan to enroll a minimum of 15 participants for each study cohort; within each cohort, participants will complete their baseline and follow-up assessments within the same 30-day window, and those in the yoga and film groups will begin and complete their respective classes at the same time. All class schedules will be fixed prior to randomization; as in our previous trials, every effort will be made to accommodate participant availability and preferences with respect to class timing.

At visit 1, an investigator will review the informed consent form with each participant in a private room; individuals still interested in participating in the study will sign the consent form. Each participant will sign two copies of the consent form, one to be given to the participant, and one to be stored with the study documents in a locked cabinet in a secure room in the WVU School of Public Health. Participant eligibility will be assessed using the IRLS (question 6) $[89,90]$ and a standardized screening checklist, similar to that used in our previous trials, which covers all of the eligibility criteria. Hemoglobin $(\mathrm{Hb})$ levels will be assessed noninvasively, using the Masimo Pronto, a simple, hand-held pulse oximetry $\mathrm{Hb}$ monitor that has demonstrated excellent reliability and precision in both clinical and healthy populations [103-106]. Reasons for ineligibility and for non-participation of eligible candidates will be documented in a screening log.

Screening evaluations will occur within 30 days prior to the start of the intervention. Participant eligibility will be assessed using a standardized screening checklist similar to that used in our previous trials, which covers the inclusion and exclusion criteria (including RLS diagnostic criteria and at least moderate RLS severity); $\mathrm{Hb}$ levels will be assessed using the Masimo Pronto, a simple, hand-held pulse oximetry $\mathrm{Hb}$ monitor that has demonstrated excellent reliability and precision [103-106].

\section{Interventions}

\section{Yoga program (active intervention)}

Participants randomized to the yoga group will complete a gentle Iyengar yoga program based on that developed and successfully implemented in our pilot studies [15, 66]. The yoga program was finalized following detailed review and input from an Iyengar Master Trainer.
Program logistics: yoga group participants will attend two 75-min classes per week for the first 4 weeks, then one 75 -min class for the remaining 8 weeks, and will be asked to complete a 30 -min homework routine 5 days/ week on non-class days. Yoga classes will be held at two yoga studios in close proximity to the WVU Health Sciences Center campus (WVU site) and OSU Center for Integrative Health and Wellness (OSU site), respectively. As in our previous trials $[15,66]$, each yoga class will begin with simple yogic centering and breathing exercises, followed by a sequence of active and restorative poses, and ending with a 10-min guided supine relaxation practice. The yoga routines, including a collective total of 25 common asanas, have been tailored for sedentary adults naïve to yoga, gradually increasing in difficulty as students progress. Pose modifications and props (e.g., chairs, blankets, and straps) will be used as needed to enable participants to perform the poses safely and easily, regardless of their level of physical ability or fitness. In addition, each class will be restricted to no more than 12 participants to allow for personalized attention. The home practice (see Table 1) will be performed with the aid of a yoga DVD and a comprehensive, indexed training manual illustrating the homework routines; These guides are based on materials developed for our preliminary trials and modified to reflect the extension to a 12-week intervention period for the proposed study. Participants will also be provided yoga mats and straps to facilitate home practice.

\section{Educational film program (comparator)}

Participants assigned to this group will attend one 75 min class per week for 12 weeks, and will be asked to complete a daily log at home recording any RLS or sleep treatments they tried based on what they learned in class or for any other reason. At the first class, film group participants will receive a comprehensive set of lay educational materials regarding RLS symptoms, causes, and epidemiology and detailing nonpharmacologic strategies for RLS management based on current national guidelines, including recommendations regarding sleep hygiene, lifestyle modifications, and behavioral approaches. Each class will be held at the WVU Health Sciences Center, and include a brief meet-and-greet period at the start of class, an instructional film segment of approximately $60 \mathrm{~min}$, and a 10-15-min group discussion, facilitated by a health educator familiar with sleep disorders and common nonpharmacologic treatments. While sitting for $75 \mathrm{~min} /$ week is unlikely to lead to worsening of symptoms in this largely sedentary population, we will, as in our previous trials, encourage participants to stand and/or stretch during the film and discussion if they so desire. All participant comments will be noted, and, together with information provided on the exit 
Table 1 Yoga home practice routines

\begin{tabular}{|c|c|}
\hline \multicolumn{2}{|c|}{ Home Practice 1: Weeks 1-3 (use wall for side-angle standing poses) } \\
\hline 1. Upward extended-leg pose & $\begin{array}{l}\text { Urdhva Prasarita } \\
\text { Padasana }\end{array}$ \\
\hline 2. Straight-leg pose: (a) bent knee $3 x$, (b) straight leg $2 x$ & $\begin{array}{l}\text { Supta } \\
\text { Padangusthasana }\end{array}$ \\
\hline $\begin{array}{l}\text { 3. Upward extended arms in mountain pose: (a) palms } \\
\text { forward, (b) palms facing }\end{array}$ & $\begin{array}{l}\text { Urdhva Hastasana in } \\
\text { Tadasana }\end{array}$ \\
\hline 4. Extended side-angle pose & $\begin{array}{l}\text { Utthita } \\
\text { Parsvakonasana }\end{array}$ \\
\hline $\begin{array}{l}\text { 5. Half-intense pose: (a) hands to wall, (b) hands on } \\
\text { chair }\end{array}$ & Ardha Uttanasana \\
\hline 6. Extended triangle pose & Utthita Trikonasana \\
\hline 7. Extended one-foot frog pose & $\begin{array}{l}\text { Utthita Eka Pada } \\
\text { Bhekasana }\end{array}$ \\
\hline 8. Seated wide-angle pose & Upavistha Konasana \\
\hline 9. Bound-angle pose & Baddha Konasana \\
\hline 10. Seated twist pose (in chair) & Bharadvajasana \\
\hline 11. Corpse pose & Savasana \\
\hline 12. Corpse pose with breathing & Savasana Pranayama \\
\hline \multicolumn{2}{|c|}{ Home Practice 2: Weeks 4-6 (use wall for side angle standing poses) } \\
\hline 1. Upward extended-leg pose & $\begin{array}{l}\text { Urdhva Prasarita } \\
\text { Padasana }\end{array}$ \\
\hline 2. Straight-leg pose: straight leg $3 x$ & $\begin{array}{l}\text { Supta } \\
\text { Padangusthasana }\end{array}$ \\
\hline $\begin{array}{l}\text { 3. Upward extended arms in mountain pose: palms } \\
\text { facing coming up from the side }\end{array}$ & $\begin{array}{l}\text { Urdhva Hastasana in } \\
\text { Tadasana }\end{array}$ \\
\hline 4. Extended side-angle pose & $\begin{array}{l}\text { Utthita } \\
\text { Parsvakonasana }\end{array}$ \\
\hline 5. Half-intense pose: hands to the wall & Ardha Uttanasana \\
\hline 6. Warrior II pose & Virabhadrasana II \\
\hline 7. Extended triangle pose & Utthita Trikonasana \\
\hline $\begin{array}{l}\text { 8. Intense pose: buttocks on the wall and hands on } \\
\text { books }\end{array}$ & Uttanasana \\
\hline 9. Extended one-foot frog pose & $\begin{array}{l}\text { Utthita Eka Pada } \\
\text { Bhekasana }\end{array}$ \\
\hline 10. Thunderbolt pose & Vajrasana \\
\hline 11. Seated wide-angle pose & Upavistha Konasana \\
\hline 12. Seated twist pose (in chair) (2 blankets) & Bharadvajasana \\
\hline 13. Supported bridge pose (2 blankets) & $\begin{array}{l}\text { Setubandha } \\
\text { Sarvangasana }\end{array}$ \\
\hline 14. Corpse pose: feet to the wall & Savasana \\
\hline 15. Corpse pose with breathing & Savasana Pranayama \\
\hline
\end{tabular}

Home Practice 3: Weeks 7-9 (no wall for side angle standing poses)

$\begin{array}{ll}\text { 1. Upward extended-leg pose } & \begin{array}{l}\text { Urdhva Prasarita } \\ \text { Padasana } \\ \text { 2. Straight-leg pose: straight leg }\end{array} \\ \begin{array}{ll}\text { Supta } \\ \text { Padangusthasana }\end{array} \\ \text { 3. Fierce pose: back to wall } & \text { Utkatasana } \\ \text { 4. Extended side-angle pose } & \begin{array}{l}\text { Utthita } \\ \text { Parsvakonasana }\end{array} \\ \text { 5. Half-intense pose: hands on books } & \text { Ardha Uttanasana } \\ \text { 6. Warrior II pose } & \text { Virabhadrasana II } \\ \text { 7. Extended triangle pose } & \text { Utthita Trikonasana } \\ \text { 8. Intense pose: holding elbows } & \text { Uttanasana } \\ \text { 9. Downward-facing dog pose: (a) hands at wall, (b) } & \text { Adho Mukha }\end{array}$

Table 1 Yoga home practice routines (Continued)

\begin{tabular}{|c|c|}
\hline heels on wall & Svanasana \\
\hline 10. Extended one-foot frog pose & $\begin{array}{l}\text { Utthita Eka Pada } \\
\text { Bhekasana }\end{array}$ \\
\hline 11. Thunderbolt pose & Vajrasana \\
\hline 12. Staff pose & Dandasana \\
\hline 13. Seated wide-angle pose & Upavistha Konasana \\
\hline 14. Bound angle pose (2 blankets) & Baddha Konasana \\
\hline 15. Seated twist pose (in chair) & $\begin{array}{l}\text { Bharadvajasana (on } \\
\text { blankets) }\end{array}$ \\
\hline 16. Supported bridge pose & $\begin{array}{l}\text { Setubandha } \\
\text { Sarvangasana }\end{array}$ \\
\hline 17. Corpse pose & Savasana \\
\hline 18. Corpse pose with breathing & Savasana Pranayama \\
\hline \multicolumn{2}{|c|}{ Home Practice 4: Weeks 10-12 (no wall for side angle standing poses) } \\
\hline 1. Upward extended-leg pose & $\begin{array}{l}\text { Urdhva Prasarita } \\
\text { Padasana }\end{array}$ \\
\hline 2. Straight-leg pose: straight leg $1 x$ & $\begin{array}{l}\text { Supta } \\
\text { Padangusthasana }\end{array}$ \\
\hline 3. Fierce pose: feet apart & Utkatasana \\
\hline 4. Extended side-angle pose & $\begin{array}{l}\text { Utthita } \\
\text { Parsvakonasana }\end{array}$ \\
\hline 5. Intense pose: holding elbows & Uttanasana \\
\hline 6. Downward-facing dog pose & $\begin{array}{l}\text { Adho Mukha } \\
\text { Svanasana }\end{array}$ \\
\hline 7. Warrior I pose: back heel at wall & Virabhadrasana I \\
\hline 8. Hero's pose & Virasana \\
\hline 9. Garland pose: (a) hold elbows, (b) extend arms & Malasana \\
\hline 10. Bound angle pose & Baddha Konasana \\
\hline 11. Head-to-knee pose & Janu Sirsasana \\
\hline 12. Western intense pose & Paschimottanasana \\
\hline 13. Active bridge pose & Chatush padasana \\
\hline 14. Corpse pose & Savasana \\
\hline 15. Corpse pose with breathing & Savasana Pranayama \\
\hline
\end{tabular}

questionnaire, will be used to refine the program for the larger trial. Upon study completion, film group participants will receive all yoga homework materials, and be offered a half-day workshop in yoga for RLS.

Course content for this standardized film education program will include information on: RLS symptoms, epidemiology, and management, including sleep hygiene practices; other sleep disorders and associated comorbidities, and on mind-body and other complementary therapies likely to be of interest to those taking part in a yoga and sleep education study. As in our previous RCT [87], educational films comprise the mainstay of the instructional program, allowing participants to be informed by nationally-recognized subject experts on a variety of topics in a professional and entertaining way. This 12-week program is designed to be easily replicable and to ensure reasonable comparability of staff attention and social interaction. The film selection procedure was similar to that successfully employed in our earlier 
studies; 41 commercially available documentary and educational films were screened for content relevance, accuracy, and likely appeal to the target study population. Each film was reviewed by three or more members of the study team, and films for inclusion in the program were selected by consensus. The program includes 11 films, including three regarding sleep, and one specific to RLS (see Table 2).

\section{Criteria for discontinuing or modifying allocated interventions for a given trial participant}

Each class will be restricted to no more than 12 participants to allow for personalized attention. In the event that a participant experiences an adverse event (AE) which makes continuation of the intervention unsafe for that individual, the study coordinator will inform the principal investigator (PI) and the study physician, referencing just the participant's study ID number, and the intervention will be discontinued for that participant. With their permission, participants will continue to be followed if the study intervention is discontinued. Any $\mathrm{AE}$ requiring discontinuation that is judged to be due to the intervention will prompt re-evaluation and possible modification of the intervention.

\section{Strategies to improve adherence to intervention protocols and procedures for monitoring adherence}

Attendance data and homework logs will be collected each week by the group instructor, and monitored for non-adherence. Instructors will query non-adherent participants to ascertain reasons for non-adherence and determine appropriate strategies to approve adherence (e.g., scheduling a different time of day for performing or recording homework, using yoga props or modified versions of poses, following the yoga routine from previous weeks if the current routine is too challenging or problematic, etc.).

\section{Relevant concomitant care and interventions that are permitted or prohibited during the trial}

As noted above, exclusion criteria include the use of anti-psychotic agents and change in dopaminergic or other central nervous system agents within the previous 3 months; any change in medication use or dosage during the trial will be monitored. In addition, participants are asked to avoid the use of any new drugs or treatments other than the assigned intervention, and are not allowed to participate in another intervention study for the duration of the trial. No concomitant interventions are required.

\section{Instructors}

All study yoga instructors have been certified in Iyengar yoga $(\geq 500 \mathrm{~h})$, with at least 3 years of experience teaching adults with a range of chronic health conditions and trained in the final RLS yoga protocol by lead study yoga teacher, Dr. Kimberly Williams. Instruction will be aided by an illustrated training manual and reference guide based on our pilot work and provided to each instructor along with the home-practice DVD.

The film intervention will be administered by a health educator versant in sleep disorders and an advanced graduate student trained for this purpose. This program, based predominantly on educational films, is designed to be easily replicable. The instructor's role is primarily to facilitate group discussion of the content presented in the films.

\section{Assignment of interventions Allocation and concealment}

The statistician, who will have no contact with the participants, generated a randomized assignment master list and provided sequentially numbered opaque envelopes containing the group assignment and corresponding study forms. The consenting team member will assign the unique number from the next envelope in sequence as the participant's study ID, and enter the number and participant name on a secure electronic database; this information will be linked to the randomization assignment, with the linked data stored in a separate password-protected database. The sealed, numbered assignment packet will be given to the participant at the conclusion of visit 1 after collection of baseline data.

\section{Randomization}

Randomization will occur immediately following completion of baseline evaluations and no more than 30 days prior to initiation of the intervention. Eligible participants will be randomized using a 1:1 ratio, to the yoga $(N=22)$ or educational film group $(N=22)$, based on an allocation sequence generated by the study statistician using a randomly varying block randomization method to ensure equal distribution among treatment groups [107].

\section{Blinding}

The majority of study personnel will be blinded to treatment assignment until the database is deidentified and locked. The randomization scheme will be devised and provided by an individual with statistical expertise who has no access to the data or influence on study outcomes; this individual will maintain the master coding sheet indicating the treatment assignment corresponding to each participant number. Following confirmation of eligibility and baseline assessment, randomization will be performed by the consenting team member, who will have no advance knowledge of treatment allocation; sealed, opaque envelopes containing information regarding the participant's assigned intervention will simply be 
Table 2 Educational film program

Special section or timing cues

Session 1

Introduction to the study and distribution of restless legs syndrome (RLS) information packets

Restless Leg Syndrome: An Uncontrollable Urge to Move (2012)

(Part of the award-winning series: Healthy Body, Healthy Mind)

Good Night with the Sleep Doctor DVD (2008) (Dr. Michael Breus)

Act 1 [end at 25:15]

Session 2

Good Night with the Sleep Doctor DVD (2008) (Dr. Michael Breus)

Acts 2 and 3

Session 3

10 Things You Should Know About Sleep (2009) (A BBC production)

Session 4

The New Medicine (2006) (FREDDIE award winner for excellence in health and wellness media)

Session 5

Mindfulness and Meditation: Stress Reduction (2000) (Jon Kabat-Zinn)

Session 6

Stress and Relaxation Explained: An Introduction to Stress Management and Relaxation Techniques (2007)

Introduction;

Part 1 (Stress): Explanations: Nature of Stress, Biological Origins, Symptoms, Health Effects; Part 2 (Relaxation): Relaxation Techniques: Mind-Body Medicine, Managing \Stress, Relaxation Techniques; Real World Balance; Part 4 (Guided relaxation)

Session 7

Yoga Unveiled: The Evolution and Essence of a Spiritual Tradition (2004)

Part 5: Yoga as Therapy

Session 8

UCSF's Mini Medical School for the Public - Health and Vitality: What

Science Tells Us About How to Thrive (2011)

Session 9

The Connection (2014)

Main section

Session 10

Happiness 101 with Tal Ben-Shahar (2009)

Main section

Session 11

The Real Age Makeover with Michael F. Roizen, MD (2005)

Part I

Session 12

The Real Age Makeover with Michael F. Roizen, MD

Q\&A [to 24:08]

Happiness 101

Sloat bonus material

The Connection

Benson Interview

uniquely numbered, with no external indication of treatment assignment; as in previous studies, participants will be instructed to open their envelopes upon exiting the building. The study coordinator will maintain the list linking participant numbers with personally identifiable information. Assessments will likewise be conducted by trained study personnel blinded to treatment allocation and specifically hired for this purpose. The yoga and educational film group instructors will be responsible for documenting attendance and collecting homework logs, as well as for contacting participants. Instructors will not have access to the data or be involved in data monitoring or analysis. Data will be entered (double-keyed) into an existing data template by two students trained in data management; participants will be identified only using a unique number.

In the unlikely event that there are three serious adverse events (SAEs) in either group that are judged to be related to the intervention, the study coordinator will inform the PI of this fact. Up to this point, the PI will be 
aware of all SAEs but will be unaware of the affected participant's group assignment. If the PI agrees that the SAEs are related to the intervention, she will determine that the blind will be broken. In that event, the study coordinator will give the list linking participant numbers with personally identifiable information to the PI.

\section{Data collection and outcomes}

Assessments will be conducted by study team members with training and experience in clinical assessment; all assessment personnel will be blinded to treatment assignment. Baseline data, including that on exploratory outcomes, will be collected prior to randomization (see "Patient timeline" below).

To determine feasibility and acceptability of the 12-week yoga and educational film comparator program, our primary aim, we will collect comprehensive information, both overall and by treatment group, on: rates of recruitment and success of different recruitment strategies, and reasons for refusal to participate; screening, randomization and enrollment rates, including reasons for screening failures and refusals to enroll/be randomized to treatment; rates of retention (completion of assessment visits) and adherence (completion of home logs and class attendance rates (yoga and film groups); completion of home practice (yoga group)); and participant satisfaction, assessed via a structured program evaluation questionnaire regarding participant perceptions of, and experiences with, the study and their respective programs. Attendance data will be collected by the instructor for each group, as will homework logs. Participants will complete the program evaluation questionnaire, modeled on that used in our previous trials $[15,87,108]$, upon completion of the 12-week intervention period or upon leaving the study.

A structured questionnaire regarding possible yoga-dosing scenarios will be administered at week 12 to determine participant preferences relative to yoga programs of varying duration and intensity ( 8 weeks, 16 classes ( $2 x /$ week); 12 weeks, 16 classes $(2 x /$ week for the first 4 weeks, $1 x /$ week thereafter); 16 weeks, 16 classes (1x/week), as well as time of year that the classes meet. Information from this questionnaire will address a secondary aim, and aid in optimizing the yoga protocol for our future studies.

Data on exploratory outcomes and certain modifying/ confounding factors will be collected at baseline and 12 weeks to determine the effect sizes of the programs, data critical to the design of the planned larger RCT. RLS symptom severity, the primary efficacy outcome for the full-scale trial, will be evaluated using the International RLS Rating Scale (IRLS), a 10-item scale which includes questions related to frequency, intensity, and impact [89]. Considered the gold standard for measuring RLS symptoms [109, 110], this instrument is recommended for use in RLS clinical trials by the European RLS Study Group (EURLSSG) [111], and is widely used both in the US and internationally [3, 112]. Additional exploratory outcomes are sleep quality, mood, and health-related quality of life (HrQOL), endpoints recommended for inclusion in all clinical trials of RLS [26, 111]. These outcomes will be assessed via a short battery of self-report instruments commonly used in pharmaceutical trials of RLS patients [113-116]. Sleep quality will be assessed using the nine-item Pittsburgh Sleep Quality Index (PSQI) [117]; mood will be evaluated using the 65-item Profile of Mood States (POMS) [118] and 10-item Perceived Stress Scale (PSS) $[119,120]$; and HrQOL will be measured using the 36-item MOS Short Form-36 (SF-36) [121, 122]. These self-report instruments are well-established scales that have been shown to be sensitive to short-term behavioral interventions, and have been validated in a wide range of populations, including RLS patients [118, 123-137]. As in our previous trials $[15,66]$ we will also assess potential changes in blood pressure and heart rate to determine effect sizes in these indices of sympathetic activation; heart rate and blood pressure will be measured three times at each assessment using an automated blood pressure monitor (Omron HEM-780) after a 5-min seated rest period.

To measure change in social support and physical activity, potential modifying or confounding variables, participants will complete the 11-item Duke Social Support Index (abbreviated form $[138,139]$ ) and 10-item Physical Activity Scale for the Elderly [140-142] (to capture physical activity other than yoga) at each visit; information on Body Mass Index (BMI, calculated as weight $(\mathrm{kg}) /$ height $\left.(\mathrm{m})^{2}\right)$, caffeine and alcohol consumption, smoking, and use of non-RLS medications will also be collected at each assessment. To assess expectation of benefit, the Credibility/Expectancy Questionnaire (CEQ) $[143,144]$ will be collected from participants after their first class. Participants will be asked to record use of other RLS treatments on their weekly logs.

\section{Patient timeline (Fig. 2)}

\section{Data management}

Completed data forms or other hard-copy documents containing protected health information will be kept in a locked file in an investigator's office. Data will be entered into an electronic deidentified database by authorized study team members, checked for completeness and accuracy. The PI or study staff will review all data collection forms on an ongoing basis for data completeness and accuracy as well as protocol compliance. Access to data with identifiers will be restricted to authorized study team members and regulatory authorities. Data verification will 


\begin{tabular}{|c|c|c|c|c|c|}
\hline Assessment & $\begin{array}{l}\text { Screening, } \\
\text { Enrollment: } \\
\text { (Day -30 to 0) }\end{array}$ & $\begin{array}{c}\text { Baseline, } \\
\text { Randomization: } \\
\text { (Day -30 to 0) }\end{array}$ & $\begin{array}{l}\text { Treatment } \\
\text { Week } 1\end{array}$ & $\begin{array}{c}\text { Treatment } \\
\text { Weeks 2-12 }\end{array}$ & $\begin{array}{l}\text { Followup: } \\
\text { Final Visit } \\
\text { (Last tx Day } \\
0 \text { to }+30 \text { ) }\end{array}$ \\
\hline Informed Consent Form & $\mathbf{x}$ & & & & \\
\hline Inclusion/Exclusion Criteria & $\mathbf{x}$ & & & & \\
\hline Demographics & & $\mathbf{x}$ & & & \\
\hline $\begin{array}{l}\text { Medical History, Lifestyle } \\
\text { Factors }\end{array}$ & & $\mathbf{x}$ & & & \\
\hline Current Medications & & $\mathbf{x}$ & & & $\mathbf{x}$ \\
\hline BMI & & $\mathbf{x}$ & & & $\mathbf{x}$ \\
\hline Vital Signs: BP, HR & & $\mathbf{x}$ & & & $\mathbf{x}$ \\
\hline Treatment expectancy (CEQ) & & $\mathbf{x}$ & & & $\mathbf{x}$ \\
\hline $\begin{array}{l}\text { Exploratory Outcome } \\
\text { Measures: IRLS, PSQI, } \\
\text { POMS, PSS, SF-36 }\end{array}$ & & $\mathbf{x}$ & & & $\mathbf{x}$ \\
\hline $\begin{array}{l}\text { Physical activity (PASE), } \\
\text { Social support (DSSI) }\end{array}$ & & $\mathbf{x}$ & & & $\mathbf{x}$ \\
\hline Enrollment/Randomization & & $\mathbf{x}$ & & & \\
\hline Adherence: Attendance Logs & & & $\mathbf{x}$ & $\mathbf{x}$ & \\
\hline $\begin{array}{l}\text { Adherence: Homework } \\
\text { (Practice/Treatment) Logs }\end{array}$ & & & & $\mathbf{x}$ & $\mathbf{x}$ \\
\hline $\begin{array}{l}\text { Program evaluation } \\
\text { questionnaire }\end{array}$ & & & & & $\mathbf{x}$ \\
\hline Yoga dosing questionnaire & & & & & $\mathbf{x}$ \\
\hline Adverse Events & & & $\mathbf{x}$ & $\mathbf{x}$ & $\mathbf{x}$ \\
\hline Retention & & & & $x$ & $\mathbf{x}$ \\
\hline Recruitment rates ${ }^{*}$ & $\mathbf{x}$ & & & & \\
\hline
\end{tabular}

Fig. 2 Schedule of evaluations. *To be monitored continuously throughout study until study is closed to enrollment. Abbreviations: BP blood pressure, BMI Body Mass Index (weight $(\mathrm{kg}) /$ height $\left.(\mathrm{m})^{2}\right)$, CEQ Credibility/Expectancy Questionnaire, HR heart rate, DSSI Duke Social Support Index, IRLS International Restless Legs Scale, PASE Physical Activity Scale for the Elderly, POMS Profile of Mood States, PSQI Pittsburgh Sleep Quality Index, PSS Perceived Stress Scale, SF-36 36-item MOS Short Form-36, Tx treatment

be performed by someone other than the individual originally collecting the data, or by double-data entry.

Electronic data will be stored on a secure server which is maintained, with regular back-ups, by WVU Health Sciences Center system administrators and accessible from password-protected computers in the WVU Department of Epidemiology. Any data, forms, and other records with identifiers that leave the site will be transported in a locked file box to maintain confidentiality. Identifiable data will be destroyed 5 years after study completion or 3 years after the last publication based on when the data is published, whichever comes last (unless future regulations dictate that the data be kept for longer).

\section{Statistical methods}

All analyses will be performed using SAS [145] or R [146]. For the primary feasibility aims, we will be evaluating recruitment and enrollment rates (all interested potential participants), acceptability of randomization (all enrolled subjects), retention, and adherence (all randomized participants). For the secondary aims, we will define the intent-to-treat (ITT) population as all subjects who are randomized with baseline assessments and at least one post-randomization assessment. The per-protocol analysis of the exploratory outcomes (RLS symptoms, sleep quality, mood, stress, and quality of life) will include all participants who completed both assessments and at least 75\% of the classes.

Feasibility of the proposed design (A.1) will be evaluated in several ways:

Recruitment: we will examine recruitment time and success rates for different recruitment strategies and assess the percentage of interested volunteers who meet the study criteria, agree to participate and are randomized. We will use Fisher's exact test to determine whether there are any differences in recruitment rates across the different strategies, and exponential regression model to assess the recruitment strategy on recruitment time.

Retention: will initially be assessed using descriptive statistics, including comparisons between retained individuals and drop-outs. The nonparametric Kaplan-Meier curve will be used to estimate the probability of 
retention over the duration of the study. If retention is unexpectedly low, we will use the proportional hazard model to assess retention differentials by treatment, demographic, and health-related factors to better target and retain specific groups in future trials.

Randomization success: (i.e., the two groups are similar demographically and on anthropometric and exploratory outcome measures at baseline) will be assessed using the one-sample run test. To evaluate adherence to the study protocol, we will determine missing-data rates at baseline and follow-up, class attendance (both groups), and completion of weekly logs.

Treatment fidelity (A.2.1) will be monitored and lapses recorded and compared between groups, along with outcomes of remediation strategies. We will use the Fisher's exact (continuous data) and chi-square tests (using benchmark cut-offs) to determine potential differences in treatment adherence and fidelity.

Treatment effect sizes (A.2.2), based on between-group differences in change over time, will be estimated using one-way ANOVA models. Effect size estimates will be calculated using both ITT (primary) and per-protocol analyses. These unbiased estimates of intervention effect size will inform sample size determination for our planned future efficacy trial [147]. Scores on the Yoga-dosing Questionnaire (A.2.3) will also be assessed using descriptive statistics to determine optimal scheduling and maximum acceptable dosing of yoga for our future trial.

Missing data: every effort will be made to minimize missing data relevant to all aims. If missing data does occur and the missing-data pattern (probability model) is not missing completely at random (MCAR), then we will consider approaches appropriate for missing at random (MAR) and missing not at random (MNAR). If the pattern or structure of the plausible missing data suggests MAR, either the EM algorithm [148], inverse weighting [149], or multiple imputation (MI) [150, 151] will be used and the missing-data mechanism will be constructed from the collected data [150, 152, 153]. The selected method will reflect the appropriateness of the method to best estimate the underlying missing-data mechanism [148-150, 152]. Participant characteristics will be assessed, including demographic and lifestyle characteristics, RLS severity, medical history, health-related factors, and baseline questionnaire scores for the estimation of plausible models (i.e., MCAR, MAR, and MNAR) for the missing-data mechanism. While we will not be able to definitively test if the missing data are MNAR, If there are indicators suggestive of MNAR (e.g., drop-outs differ significantly from non-drop-outs in key characteristics), we will use MI in conjunction with a sensitivity analysis to provide a set of plausible conclusions recognizing that each conclusion will be predicated on the assumptions necessary for constructing a MNAR missing-data mechanism model $[150,153]$.

\section{Data monitoring, harms, and auditing}

The frequency of data review for this study differs according to the type of data and can be summarized as follows: data on accrual, status of all enrolled subjects, adherence, and AEs will be reviewed by the PI and study coordinator every 4 months; accrual and AEs will also be reviewed yearly by the PI, IRB, Independent Monitoring Committee (IMC) (comprising three experts with appropriate expertise and experience in clinical trials, biostatistics, and clinical medicine), and $\mathrm{NCCIH}$; SAEs will be reviewed per occurrence by all.

While both programs are minimal risk interventions, we are further ensuring participant safety by: using highly trained Iyengar instructors experienced in teaching adults with chronic health conditions and in adapting poses to minimize discomfort and risk of injury; including only gentle postures in the program; and maintaining small class sizes to ensure adequate personalized attention. In addition, all participants will be encouraged to report any AEs to study staff and on their yoga and co-intervention logs. Yoga group participants will also be queried about AEs by the yoga instructors during class. Yoga instructors will notify the study coordinator regarding any $\mathrm{AE}$.

The study coordinator will promptly report AEs to the IRB according to protocol and IRB policies; complete an adverse events form and grade the $\mathrm{AE}$; and contact the participant by telephone on a weekly basis to monitor the event until the event resolves, the study is completed, or the participant is removed from the study. In addition, subjects can choose to stop the study at any time. Any serious and unexpected AEs will require re-evaluation of the risk of the study. Monitoring and aggregate review will be performed by the PI, IRB, and IMC through annual review.

\section{Stopping rules}

This study will be stopped prior to its completion if: (1) the intervention is associated with adverse effects that call into question the safety of the intervention; (2) any new information becomes available during the trial that necessitates stopping the trial; or (3) other situations occur that might warrant stopping the trial. Because this RCT is specifically designed to be a feasibility study, and we will be investigating recruitment rates and optimal recruitment strategies as part of our primary aim, slow accrual would not comprise a justification for stopping the trial.

In addition, the study may be discontinued at any time by the IRB, NCCIH, the OHRP, or other government agencies as part of their duties to ensure that research participants are protected. 


\section{Discussion}

In summary, RLS is a common and burdensome sleep disorder associated with profound impairment of health, well-being, and quality of life, and with significant personal, societal, and economic burden $[6,7,26]$. There is no cure for RLS, and current front-line drug therapies can carry severe side effects. If, as our promising preliminary data suggests, yoga ultimately proves feasible and effective in reducing RLS symptoms and symptom burden, yoga will offer a novel, safe, and likely cost-effective approach to RLS prevention and management, targeting not only RLS symptoms, but also likely contributing factors and common comorbidities.

This study will lay the essential groundwork for a planned larger RCT to determine the efficacy of a yoga program for reducing symptoms and the associated burden of RLS, a common and potentially debilitating sleep disorder. Specifically, central goals of this trial include evaluating the feasibility and acceptability of a 12-week RCT of yoga vs. an attention control, and optimizing the yoga protocol for a planned larger trial of yoga for RLS management; we will also obtain effect size estimates for specific outcomes of relevance to RLS management, information critical to designing and powering our planned future study. Based on our strong pilot data, the study is consistent with the urgent national need to curtail spiraling health care costs and to identify sustainable, potentially cost-effective new approaches to chronic disease management. If the findings of the current trial and the subsequent larger RCT are positive, this study will also help support a new approach to clinical treatment of this challenging disorder, help foster improved understanding of RLS etiology, and ultimately contribute to reducing the individual, societal, and economic burden associated with this condition.

\section{Ethics and dissemination}

This study has been approved by the West Virginia University Institutional Review Board (IRB\#1505699758). No significant changes will be made to this protocol without the prior approval of the WVU IRB and the NCCIH. As described above, each participant will provide written informed consent prior to the initiation of baseline assessments or the intervention.

\section{Confidentiality}

During this study, medical history, vital signs, and assessment questionnaires will be completed at baseline and at regular intervals during the study. All of the material collected are for research purposes only, and data will be kept in strict confidence. Information will not be released without written permission of the participant, except as necessary for monitoring by the IRB, the $\mathrm{NCCIH}$, the OHRP, and the IMC. Confidentiality will be ensured by use of identification codes. This data, collected at the assessment visits, will be identified with a study identification code unique to the subject.

\section{Dissemination plans}

Upon completion of the trial, the authors plan to present the study findings at conferences aimed at physicians typically treating patients with RLS, and at other integrative health care practitioners such as yoga therapists. In addition, the investigators plan to submit our findings for publication in relevant peer-reviewed journals; we do not intend to hire professional writers.

\section{Trial status}

This trial is currently open for enrollment.

\section{Additional file}

Additional file 1: Standard Protocol Items: Recommendations for Interventional Trials (SPIRIT) Checklist. (DOC 123 kb)

\section{Abbreviations}

BMI: Body Mass Index (weight $\left.(\mathrm{kg}) / h e i g h t(\mathrm{~m})^{2}\right)$; BP: Blood pressure; CEQ: Credibility/Expectancy Questionnaire; DSSI: Duke Social Support Index HR: Heart rate; IRLS: International Restless Legs Scale; PASE: Physical Activity Scale for the Elderly; POMS: Profile of Mood States; PSQI: Pittsburgh Sleep Quality Index; PSS: Perceived Stress Scale; SF-36: 36-item MOS Short Form-36; Tx: Treatment

\section{Acknowledgements}

The authors would like to acknowledge Dr. Kimberly Williams for her contributions to the yoga program.

\section{Funding}

This project has been funded by the National Institutes of Health, National Center for Complementary and Integrative Health (grant numbers 1 R15 AT008606-01A1 and 3 R15 AT008606-01A1S1). The funding body will have no role in the collection, analysis, and interpretation of data.

Availability of data and materials

Program materials are provided as tables within this manuscript. Upon study closure, data will be made available at ClinicalTrials.gov as per the requirements of all registered trials.

\section{Authors' contributions}

TKS and KEI conceived and designed the study and drafted the study protocol. TKS drafted the manuscript. KEl provided background and rationale, along with other key content, and critically reviewed the manuscript. SW provided statistical content. KS provided important feedback on the initial study design and rationale. MK provided critical input on the protocol. All authors reviewed and approved the final version of the manuscript.

Ethics approval and consent to participate

As described above, this study has been approved by the West Virginia University Institutional Review Board (IRB\#1505699758) and each participant will provide written informed consent prior to the initiation of baseline assessments or the intervention.

Consent for publication

Not applicable.

Competing interests

The authors declare that they have no competing interests. 


\section{Publisher's Note}

Springer Nature remains neutral with regard to jurisdictional claims in published maps and institutional affiliations.

\section{Author details}

${ }^{1}$ Health Science Center Libraries, University of Florida, PO Box 100206 Gainesville, FL 32610, USA. ${ }^{2}$ Department of Biostatistics, West Virginia University School of Public Health, HSC N, PO Box 9190, Morgantown, WV 26506, USA. ${ }^{3}$ Kaiser Permanente Washington Health Research Institute, Seattle, WA, USA. ${ }^{4}$ Department of Family Medicine, The Ohio State University College of Medicine, Columbus, OH, USA. ${ }^{5}$ Department of Epidemiology, West Virginia University School of Public Health, HSC N, PO Box 9190, Morgantown, WV 26506, USA.

\section{Received: 14 September 2018 Accepted: 21 January 2019} Published online: 15 February 2019

\section{References}

1. Allen RP, Picchietti D, Hening WA, Trenkwalder C, Walters AS, Montplaisi J. Restless Legs Syndrome D, Epidemiology workshop at the National Institutes of Health, International Restless Legs Syndrome Study Group. Restless legs syndrome: diagnostic criteria, special considerations, and epidemiology. A report from the restless legs syndrome diagnosis and epidemiology workshop at the National Institutes of Health. Sleep Med. 2003;4(2):101-19.

2. Innes KE, Selfe TK, Agarwal P. Restless legs syndrome and conditions associated with metabolic dysregulation, sympathoadrenal dysfunction, and cardiovascular disease risk: a systematic review. Sleep Med Rev. 2012;16(4): 309-39.

3. Innes KE, Selfe TK, Agarwal P. Prevalence of restless legs syndrome in North American and Western European populations: a systematic review. Sleep Med. 2011;12(7):623-34.

4. Access Economics Pty. Restless legs syndrome: costs of the most common medical condition most people have never heard of. Sydney: Restless Legs Syndrome Australia. 2005. p. 1-50.

5. Allen RP, Bharmal M, Calloway M. Prevalence and disease burden of primary restless legs syndrome: results of a general population survey in the United States. Mov Disord. 2011;26(1):114-20.

6. Reese JP, Stiasny-Kolster K, Oertel WH, Dodel RC. Health-related quality of life and economic burden in patients with restless legs syndrome. Expert Rev Pharmacoecon Outcomes Res. 2007;7(5):503-21.

7. Reinhold T, Müller-Riemenschneider F, Willich SN, Brüggenjürgen B. Economic and human costs of restless legs syndrome. Pharmacoeconomics. 2009;27(4):267-79.

8. Winkelman JW. Considering the causes of RLS. Eur J Neurol. 2006;3:8-14.

9. Walters AS, Rye DB. Review of the relationship of restless legs syndrome and periodic limb movements in sleep to hypertension, heart disease, and stroke. Sleep. 2009;32(5):589-97.

10. Smith JE, Tolson JM. Recognition, diagnosis, and treatment of restless legs syndrome. J Am Acad Nurse Pract. 2008;20(8):396-401.

11. Matthews WB. Letter: Iron deficiency and restless legs. Br Med J. 1976; 1(6014):898.

12. Sandyk R. The restless legs syndrome (Ekbom's syndrome). S Afr Med J. 1983;63(18):701-2.

13. O'Keeffe ST. Restless legs syndrome. A review. Arch Intern Med. 1996;156(3):243-8.

14. Allen R. Dopamine and iron in the pathophysiology of restless legs syndrome (RLS). Sleep Med. 2004;5(4):385-91.

15. Innes KE, Selfe TK. The effects of a gentle yoga program on sleep, mood, and blood pressure in older women with Restless Legs Syndrome (RLS): a preliminary randomized controlled trial. Evid Based Complement Alternat Med. 2012;2012:294058.

16. Hening WA, Allen RP, Chaudhuri KR, Hornyak M, Lee HB, Winkelman J, Yoakum R. Clinical significance of RLS. Mov Disord. 2007;22(Suppl 18):S395-400.

17. Garcia-Borreguero D. Time to REST: epidemiology and burden. Eur J Neurol. 2006;13(Suppl 3):15-20.

18. Hening W, Walters AS, Allen RP, Montplaisir J, Myers A, Ferini-Strambi L. Impact, diagnosis and treatment of restless legs syndrome (RLS) in a primary care population: the REST (RLS epidemiology, symptoms, and treatment) primary care study.[see comment]. Sleep Med. 2004;5(3):237-46.
19. Hornyak M, Kopasz M, Berger M, Riemann D, Voderholzer U. Impact of sleep-related complaints on depressive symptoms in patients with restless legs syndrome. J Clin Psychiatry. 2005;66(9):1139-45.

20. Garcia-Borreguero D, Stillman $P$, Benes $H$, Buschmann $H$, Chaudhuri KR, Gonzalez Rodriguez VM, Hogl B, Kohnen R, Monti GC, Stiasny-Kolster K, et al. Algorithms for the diagnosis and treatment of restless legs syndrome in primary care. BMC Neurol. 2011;11:28.

21. Wesstrom J, Nilsson S, Sundstrom-Poromaa I, Ulfberg J. Restless legs syndrome among women: prevalence, co-morbidity and possible relationship to menopause. Climacteric. 2008;11(5):422-8.

22. Ulfberg J, Bjorvatn B, Leissner L, Gyring J, Karlsborg M, Regeur L, Skeidsvoll $\mathrm{H}$, Polo O, Partinen M. Comorbidity in restless legs syndrome among a sample of Swedish adults. Sleep Med. 2007;8(7/8):768-72.

23. Hornyak M. Depressive disorders in restless legs syndrome: epidemiology, pathophysiology and management. CNS Drugs. 2010;24(2):89-98.

24. Sateia MJ. Update on sleep and psychiatric disorders. Chest. 2009;135(5):1370-9.

25. Ekbom K, Ulfberg J. Restless legs syndrome. J Intern Med. 2009;266(5):419-31.

26. Earley CJ, Silber MH. Restless legs syndrome: understanding its consequences and the need for better treatment. Sleep Med. 2010;11(9):807-15.

27. Allen RP, Stillman P, Myers AJ. Physician-diagnosed restless legs syndrome in a large sample of primary medical care patients in western Europe: prevalence and characteristics. Sleep Med. 2010;11(1):31-7.

28. Happe S, Reese JP, Stiasny-Kolster K, Peglau I, Mayer G, Klotsche J, Giani G, Geraedts M, Trenkwalder C, Dodel R. Assessing health-related quality of life in patients with restless legs syndrome. Sleep Med. 2009;10(3):295-305.

29. Abetz L, Allen R, Follet A, Washburn T, Earley C, Kirsch J, Knight H. Evaluating the quality of life of patients with restless legs syndrome. Clin Ther. 2004;26(6):925-35.

30. Trenkwalder C, Hening WA, Montagna P, Oertel WH, Allen RP, Walters AS, Costa J, Stiasny-Kolster K, Sampaio C. Treatment of restless legs syndrome: an evidence-based review and implications for clinical practice. Mov Disord. 2008;23(16):2267-302.

31. Garcia-Borreguero D, Kohnen R, Silber MH, Winkelman JW, Earley CJ, Hogl B, Manconi M, Montplaisir J, Inoue Y, Allen RP. The long-term treatment of restless legs syndrome/Willis-Ekbom disease: evidence-based guidelines and clinical consensus best practice guidance: a report from the International Restless Legs Syndrome Study Group. Sleep Med. 2013;14(7):675-84.

32. Oertel WH, Trenkwalder C, Zucconi M, Benes H, Borreguero DG, Bassetti C, Partinen M, Ferini-Strambi L, Stiasny-Kolster K. State of the art in restless legs syndrome therapy: practice recommendations for treating restless legs syndrome. Mov Disord. 2007;22(Suppl 18):S466-75.

33. Berger K. What is clinically significant RLS and who decides about its treatment? Sleep Med. 2011;11(1):9-10.

34. Pourcher E, Rémillard S, Cohen H. Compulsive habits in restless legs syndrome patients under dopaminergic treatment. J Neurol Sci. 2010;290(1/2):52-6.

35. Allen RP, Ondo WG, Ball E, Calloway MO, Manjunath R, Higbie RL, Lee MR, Nisbet PA. Restless legs syndrome (RLS) augmentation associated with dopamine agonist and levodopa usage in a community sample. Sleep Med. 2011;12(5):431-9.

36. Allen RP, Earley CJ. Restless legs syndrome: a review of clinical and pathophysiologic features. J Clin Neurophysiol. 2001;18(2):128-47.

37. Clark MM. Restless legs syndrome. J Am Board Fam Pract. 2001;14(5):368-74.

38. Schapira $\mathrm{AH}$. Restless legs syndrome: an update on treatment options. Drugs. 2004;64(2):149-58.

39. Wetter TC, Winkelmann J, Eisensehr I. Current treatment options for restless legs syndrome. Expert Opin Pharmacother. 2003;4(10):1727-38.

40. García-Borreguero D, Williams A-M. Dopaminergic augmentation of restless legs syndrome. Sleep Med Rev. 2010;14(5):339-46.

41. Buckner AC. The use of dopamine agonist in the treatment of Restless Legs Syndrome: caution for practitioners and bipolar patients. South Med J. 2008; 101(8):785.

42. Spiegelhalder K, Hornyak M. Restless legs syndrome in older adults. Clin Geriatr Med. 2008;24(1):167.

43. Wilt TJ, Macdonald R, Ouellette J, Khawaja IS, Rutks I, Butler M, Fink HA. Pharmacologic therapy for primary Restless Legs Syndrome: a systematic review and meta-analysis. JAMA Intern Med. 2013;173(7):496-505.

44. Inoue $Y$, Uchimura N, Kuroda K, Hirata K, Hattori N. Long-term efficacy and safety of gabapentin enacarbil in Japanese restless legs syndrome patients. Prog Neuro-Psychopharmacol Biol Psychiatry. 2012;36(2):251-7.

45. Milligan SA, Chesson AL. Restless legs syndrome in the older adult: diagnosis and management. Drugs Aging. 2002;19(10):741-51. 
46. Wolkove N, Elkholy O, Baltzan M, Palayew M. Sleep and aging: 2. Management of sleep disorders in older people. CMAJ. 2007;176(10):1449-54.

47. Cochen V, Arbus C, Soto ME, Villars H, Tiberge M, Montemayor T, Hein C, Veccherini MF, Onen SH, Ghorayeb I, et al. Sleep disorders and their impacts on healthy, dependent, and frail older adults. J Nutr Health Aging. 2009; 13(4):322-9.

48. Winkelman JW, Johnston L. Augmentation and tolerance with long-term pramipexole treatment of restless legs syndrome (RLS).[see comment]. Sleep Med. 2004;5(1):9-14

49. Garcia-Borreguero D, Allen R, Kohnen R, Benes H, Winkelman J, Högl B, Ferini-Strambi L, Zucconi M, Trenkwalder C. Loss of response during longterm treatment of restless legs syndrome: Guidelines approved by the International Restless Legs Syndrome Study Group for use in clinical trials. Sleep Med. 2010;11(9):956-9.

50. Högl B, García-Borreguero D, Kohnen R, Ferini-Strambi L, Hadjigeorgiou G, Hornyak M, Weerd A, Happe S, Stiasny-Kolster K, Gschliesser V, et al. Progressive development of augmentation during long-term treatment with levodopa in restless legs syndrome: results of a prospective multicenter study. J Neurol. 2010;257(2):230-7.

51. Finucane TE. Evidence-based recommendations for the assessment and management of sleep disorders in older persons. J Am Geriatr Soc. 2009; 57(11):2173-4

52. Innes KE, Selfe TK, Agarwal P, Williams K, Flack KL. Efficacy of an eight-week yoga intervention on symptoms of restless legs syndrome (RLS): a pilot study. J Altern Complement Med. 2013;19(6):527-35.

53. Sakkas GK, Hadjigeorgiou GM, Karatzaferi C, Maridaki MD, Giannaki CD, Mertens PR, Rountas C, Vlychou M, Liakopoulos V, Stefanidis I. Intradialytic aerobic exercise training ameliorates symptoms of restless legs syndrome and improves functional capacity in patients on hemodialysis: a pilot study. ASAIO J (Am Soc Artif Intern Organs: 1992). 2008;54(2):185-90.

54. Aukerman MM, Aukerman D, Bayard M, Tudiver F, Thorp L, Bailey B. Exercise and restless legs syndrome: a randomized controlled trial. J Am Board Fam Med. 2006;19(5):487-93.

55. Hornyak M, Grossman C, Kohnen R, Schlatterer M, Richter H, Voderholzer U, Riemann D, Berger M. Cognitive behavioural group therapy to improve patients' strategies for coping with restless legs syndrome: a proof-ofconcept trial. J Neurol Neurosurg Psychiatry. 2008;79(7):823-5.

56. Restless Legs Syndrome Foundation. RLS Medical Bulletin. Rochester: Restless Legs Syndrome Foundation; 2011. p. 1-13.

57. Garcia-Borreguero D, Larrosa O, de la Llave Y, Verger K, Masramon X, Hernandez G. Treatment of restless legs syndrome with gabapentin: a double-blind, cross-over study. Neurology. 2002;59(10):1573-9.

58. Saletu M, Anderer P, Hogl B, Saletu-Zyhlarz G, Kunz A, Poewe W, Saletu B. Acute double-blind, placebo-controlled sleep laboratory and clinical followup studies with a combination treatment of rr-L-dopa and sr-L-dopa in restless legs syndrome. J Neural Transm. 2003;110(6):611-26.

59. McCormack PL, Siddiqui MA. Pramipexole: in restless legs syndrome. CNS Drugs. 2007;21(5):429-37 discussion 438-440

60. Inoue Y, Kuroda K, Hirata K, Uchimura N, Kagimura T, Shimizu T. Long-term open-label study of pramipexole in patients with primary restless legs syndrome. J Neurol Sci. 2010;294(1-2):62-6.

61. Bogan RK, Fry JM, Schmidt MH, Carson SW, Ritchie SY. Ropinirole in the treatment of patients with restless legs syndrome: a US-based randomized, double-blind, placebo-controlled clinical trial. Mayo Clin Proc. 2006;81(1):17-27.

62. Baker WL, White CM, Coleman Cl. Effect of nonergot dopamine agonists on symptoms of restless legs syndrome. Ann Fam Med. 2008;6(3):253-62.

63. Gold M, Siegel J, Russell L, Weinstein M, editors. Cost-effectiveness in health and medicine. New York: Oxford University Press; 1996.

64. Garfinkel M, Schumacher HJ. Yoga. Rheum Dis Clin N Am. 2000;26(1):125-32.

65. Barnes PM, Bloom B. Complementary and alternative medicine use among adults and children: United States, 2007. Natl Health Stat Rep. 2008;12:1-24.

66. Innes KE, Selfe TK, Agarwal P, Williams K, Flack KL. Efficacy of an 8-week yoga intervention on symptoms of Restless Legs Syndrome (RLS): a pilot study. J Altern Complement Med. 2013;19(3):139-46.

67. Chandwani KD, Thornton B, Perkins GH, Arun B, Raghuram NV, Nagendra HR, Qi W, Cohen L. Yoga improves quality of life and benefit finding in women undergoing radiotherapy for breast cancer. J Soc Integr Oncol. 2010;8(2):43-55.

68. Oken BS, Zajdel D, Kishiyama S, Flegal K, Dehen C, Haas M, Kraemer DF, Lawrence J, Leyva J. Randomized, controlled, six-month trial of yoga in healthy seniors: effects on cognition and quality of life. Altern Ther Health Med. 2006;12(1):40-7.

69. Agarwal R, Aradhana R, Hussain S, Beniwal R, Sabir M, Kochar D. Influence of yogic treatment on quality of life outcomes, glycaemic control and risk factors in diabetes mellitus. Int J Diabetes Dev C. 2003;23:130-4.

70. Malathi A, Damodaran A, Shah N, Patil N, Maratha S. Effect of yogic practices on subjective well being. [Clinical Trial]. Indian J Physiol Pharmacol. 2000;44(2):202-6.

71. Tüzün S, Aktas I, Akarirmak U, Sipahi S, Tüzün F. Yoga might be an alternative training for the quality of life and balance in postmenopausal osteoporosis. Eur J Phys Rehabil Med. 2010;46(1):69-72.

72. Saper RB, Sherman KJ, Cullum-Dugan D, Davis RB, Phillips RS, Culpepper L. Yoga for chronic low back pain in a predominantly minority population: a pilot randomized controlled trial. Altern Ther Health Med. 2009;15(6):18-27.

73. Bosch PR, Traustadóttir T, Howard P, Matt KS. Functional and physiological effects of yoga in women with rheumatoid arthritis: a pilot study. Altern Ther Health Med. 2009;15(4):24-31.

74. John PJ, Sharma N, Sharma CM, Kankane A. Effectiveness of yoga therapy in the treatment of migraine without aura: a randomized controlled trial. Headache. 2007;47(5):654-61.

75. Williams KA, Petronis J, Smith D, Goodrich D, Wu J, Ravi N, Doyle EJ Jr, Gregory Juckett R, Munoz Kolar M, Gross R, et al. Effect of lyengar yoga therapy for chronic low back pain. Pain. 2005;115(1-2):107-17.

76. Yang K. A review of yoga programs for four leading risk factors of chronic diseases. Evid Based Complement Alternat Med. 2007;4(4):487-91.

77. Ross A, Thomas S. The health benefits of yoga and exercise: a review of comparison studies. J Altern Complement Med. 2010;16(1):3-12.

78. Innes K, Selfe T, Taylor A. Menopause, the metabolic syndrome, and mindbody therapies. Menopause. 2008;15(5):1005-13.

79. Hagins M, States R, Selfe T, Innes K. Effectiveness of yoga for hypertension: systematic review and meta-analysis. Evid Based Complement Alternat Med. 2013;2013:649836.

80. Posadzki P, Cramer H, Kuzdzal A, Lee MS, Ernst E. Yoga for hypertension: a systematic review of randomized clinical trials. Complement Ther Med. 2014;22(3):511-22.

81. Yurtkuran M, Alp A, Dilek K. A modified yoga-based exercise program in hemodialysis patients: a randomized controlled study. Complement Ther Med. 2007;15(3):164-71.

82. Greendale GA, Huang M, Karlamangla AS, Seeger L, Crawford S. Yoga decreases kyphosis in senior women and men with adult-onset hyperkyphosis: results of a randomized controlled trial. J Am Geriatr Soc. 2009;57(9):1569-79.

83. Innes KE, Vincent HK. The influence of yoga-based programs on risk profiles in adults with type 2 diabetes mellitus: a systematic review. Evid Based Complement Alternat Med. 2007;4(4):469-86.

84. Telles S, Naveen KV. Yoga for rehabilitation: an overview. Indian J Med Sci. 1997;51(4):123-7.

85. Bower JE, Woolery A, Sternlieb B, Garet D. Yoga for cancer patients and survivors. Cancer Control. 2005;12(3):165-71.

86. DiBenedetto M, Innes K, Taylor A, Rodeheaver P, Boxer J, Wright J, Kerrigan C. Effect of yoga on gait in the elderly. Arch Phys Med Rehabil. 2005;86: 1830-7.

87. Innes KE, Selfe TK, Alexander GK, Taylor AG. A new educational film control for use in studies of active mind-body therapies: acceptability and feasibility. J Altern Complement Med. 2011;17(5):453-8.

88. Uzun S, Kozumplik O, Jakovljevic M, Sedic B. Side effects of treatment with benzodiazepines. Psychiatr Danub. 2010;22(1):90-3.

89. Walters AS, LeBrocq C, Dhar A, Hening W, Rosen R, Allen RP, Trenkwalder C. Validation of the International Restless Legs Syndrome Study Group rating scale for restless legs syndrome. Sleep Med. 2003;4(2):121-32.

90. Hening WA, Allen RP. Restless legs syndrome (RLS): the continuing development of diagnostic standards and severity measures. Sleep Med. 2003;4:95.

91. Benes $H$, Walters AS, Allen RP, Hening WA, Kohnen R. Definition of restless legs syndrome, how to diagnose it, and how to differentiate it from RLS mimics. Mov Disord. 2007;22(Suppl 18):S401-8.

92. Inoue Y, Kuroda K, Hirata K, Uchimura N, Kagimura T, Shimizu T. Efficacy, safety and dose-response of pramipexole in Japanese patients with primary restless legs syndrome: randomized trial. Neuropsychobiology. 2011;63(1):35-42. 
93. Oertel WH, Stiasny-Kolster K, Bergtholdt B, Hallstrom Y, Albo J, Leissner L, Schindler T, Koester J, Reess J. Efficacy of pramipexole in restless legs syndrome: a six-week, multicenter, randomized, double-blind study (effect-RLS study). Mov Disord. 2007;22(2):213-9.

94. Partinen M, Hirvonen K, Jama L, Alakuijala A, Hublin C, Tamminen I, Koester $\mathrm{J}$, Reess J. Efficacy and safety of pramipexole in idiopathic restless legs syndrome: a polysomnographic dose-finding study — the PRELUDE study. Sleep Med. 2006;7(5):407-17.

95. Trenkwalder C, Benes H, Poewe W, Oertel WH, Garcia-Borreguero D, de Weerd AW, Ferini-Strambi L, Montagna P, Odin P, Stiasny-Kolster K, et al. Efficacy of rotigotine for treatment of moderate-to-severe restless legs syndrome: a randomised, double-blind, placebo-controlled trial. Lancet Neurol. 2008;7(7):595-604.

96. Winkelman JW, Sethi KD, Kushida CA, Becker PM, Koester J, Cappola JJ, Reess J. Efficacy and safety of pramipexole in restless legs syndrome. Neurology. 2006;67(6):1034-9.

97. Williams K, Abildso C, Steinberg L, Doyle E, Epstein B, Smith D, Hobbs G, Gross R, Kelley G, Cooper L. Evaluation of the effectiveness and efficacy of lyengar yoga therapy on chronic low back pain. Spine (Phila Pa 1976). 2009; 34(19):2066-76.

98. Lucas AR, Focht BC, Cohn DE, Buckworth J, Klatt MD. A Mindfulness-based lifestyle intervention for obese, inactive endometrial cancer survivors: a feasibility study. Integr Cancer Ther. 2016;16(3):263-275.

99. Steinberg BA, Klatt M, Duchemin AM. Feasibility of a mindfulness-based intervention for surgical intensive care unit personnel. Am J Crit Care. 2017; 26(1):10-8.

100. Klatt M, Norre C, Reader B, Yodice L, White S. Mindfulness in motion: a mindfulness-based intervention to reduce stress and enhance quality of sleep in Scandinavian employees. Mindfulness. 2017:8(2):481-8.

101. Malarkey WB, Jarjoura D, Klatt M. Workplace based mindfulness practice and inflammation: a randomized trial. Brain Behav Immun. 2013;27(1):145-54.

102. Gilbertson RM, Klatt MD. Mindfulness in motion for people with multiple sclerosis: a feasibility study. Int J MS Care. 2017;19(5):225-31.

103. Frasca D, Dahyot-Fizelier C, Catherine K, Levrat Q, Debaene B, Mimoz O. Accuracy of a continuous noninvasive hemoglobin monitor in intensive care unit patients. Crit Care Med. 2011;39(10):2277-82.

104. Barker SJ. "Motion-resistant" pulse oximetry: a comparison of new and old models. Anesth Analg. 2002;95(4):967-72 table of contents.

105. Ehrenfeld J, Henneman J. Impact of continuous and noninvasive hemoglobin monitoring on intraoperative blood transfusions. In: Proceeding of the 2010 Annual Meeting of the American Society of Anesthesiologists; 2010. Abs LB05.

106. Accuracy of Noninvasive Spot-Checking of Total Hemoglobin with the Masimo Pronto-7. Technical Bulletin: Masimo FDA 510(k) Clearance Submission Data 2010. http://www.infiniti.no/upload/Produktblad/Masimo/ MAS_PB_pronto-7_tech_bulletin.pdf. Accessed 3 Feb 2019.

107. Vickers AJ. How to randomize. J Soc Integr Oncol. 2006;4(4):194-8.

108. Innes KE, Selfe TK, Brown C, Rose K, Thompson-Heisterman A. The effects of meditation on perceived stress and related indices of psychological status and sympathetic activation in persons with Alzheimer's disease and their caregivers: a pilot study. Evid Based Complement Alternat Med. 2012;2012:927509.

109. Kohnen R, Allen RP, Benes H, Garcia-Borreguero D, Hening WA, StiasnyKolster K, Zucconi M. Assessment of restless legs syndrome-methodological approaches for use in practice and clinical trials. Mov Disord. 2007;22(Suppl 18):S485-94.

110. Hogl B, Gschliesser V. RLS assessment and sleep questionnaires in practice-lessons learned from Parkinson's disease. Sleep Med. 2007;8(Suppl 2):S7-12.

111. Trenkwalder $C$, Kohnen R, Allen RP, Benes H, Ferini-Strambi L, GarciaBorreguero D, Hadjigeorgiou GM, Happe S, Hogl B, Hornyak M, et al. Clinical trials in restless legs syndrome-recommendations of the European RLS Study Group (EURLSSG). Mov Disord. 2007;22(Suppl 18):S495-504.

112. Innes KE, Selfe TK, Agarwal P. Restless legs syndrome and conditions associated with metabolic dysregulation, sympathoadrenal dysfunction, and cardiovascular disease risk: a systematic review. Sleep Med Rev. 2011;38(5):1-31.

113. Conti CF, de Oliveira MM, Andriolo RB, Saconato H, Atallah AN, Valbuza JS, Coin de Carvalho LB, do Prado GF. Levodopa for idiopathic restless legs syndrome: evidence-based review. Mov Disord. 2007;22(13):1943-51.

114. Conti CF, Oliveira MM, Valbuza JS, LBF P, Carvalho LBC, Prado GF. Anticonvulsants to treat idiopathic restless legs syndrome: systematic review. Arq Neuropsiquiatr. 2008;66(2B):431-5.
115. Montagna P, Hornyak M, Ulfberg J, Hong SB, Koester J, Crespi G, Albrecht S. Randomized trial of pramipexole for patients with restless legs syndrome (RLS) and RLS-related impairment of mood. Sleep Med. 2011;12(1):34-40.

116. Kushida CA. Ropinirole for the treatment of restless legs syndrome. Neuropsychiatr Dis Treat. 2006;2(4):407-19.

117. Buysse DJ, Reynolds CF 3rd, Monk TH, Berman SR, Kupfer DJ. The Pittsburgh Sleep Quality Index: a new instrument for psychiatric practice and research. Psychiatry Res. 1989;28(2):193-213.

118. Berger BG, Motl RW. Exercise and mood: a selective review and synthesis of research employing the Profile of Mood States. J Appl Sport Psychol. 2000; 12(1):69-92.

119. Cohen S, Kamararck T, Mermelstein R. A global measure of perceived stress. J Health Soc Behav. 1983;24(4):385-96.

120. Cohen S. Perceived stress in a probability sample of the United States. In: The social psychology of health. Spacapan S, Oskamp S, eds. Thousand Oaks: Sage Publications; 1988: 31-67.

121. Ware JE Jr, Sherbourne CD. The MOS 36-item short-form health survey (SF-36). I. Conceptual framework and item selection. Med Care. 1992; 30(6):473-83.

122. Ware JE Jr, Gandek B. Overview of the SF-36 Health Survey and the International Quality of Life Assessment (IQOLA) Project. J Clin Epidemiol. 1998;51(11):903-12.

123. Lane JD, Seskevich JE, Pieper CF. Brief meditation training can improve perceived stress and negative mood. Altern Ther Health Med. 2007; 13(1):38-44.

124. Blake $H$, Lincoln NB, Clarke DD. Caregiver strain in spouses of stroke patients. Clin Rehabil. 2003;17(3):312-7.

125. Foreman MD, Fletcher K, Mion LC, Simon L. Assessing cognitive function. Geriatr Nurs. 1996;17(5):228-32 quiz 233

126. Aschbacher K, Patterson TL, von Kanel R, Dimsdale JE, Mills PJ, Adler KA, Ancoli-Israel S, Grant I. Coping processes and hemostatic reactivity to acute stress in dementia caregivers. Psychosom Med. 2005;67(6):964-71.

127. Carlson LE, Speca M, Patel KD, Goodey E. Mindfulness-based stress reduction in relation to quality of life, mood, symptoms of stress, and immune parameters in breast and prostate cancer outpatients. Psychosom Med. 2003;65(4):571-81.

128. Strodl E, Kenardy J, Aroney C. Perceived stress as a predictor of the selfreported new diagnosis of symptomatic CHD in older women. Int J Behav Med. 2003;10(3):205-20.

129. Fitzsimmons S, Buettner LL. Health promotion for the mind, body, and spirit: a college course for older adults with dementia. Am J Alzheimers Dis Other Demen. 2003;18(5):282-90.

130. Annesi JJ. Changes in depressed mood associated with 10 weeks of moderate cardiovascular exercise in formerly sedentary adults. Psychol Rep. 2005;96(3 Pt 1):855-62

131. Johnson SK, Frederick J, Kaufman M, Mountjoy B. A controlled investigation of bodywork in multiple sclerosis. J Altern Complement Med. 1999;5(3):237-43.

132. Walters SJ, Munro JF, Brazier JE. Using the SF-36 with older adults: a crosssectional community-based survey. Age Ageing. 2001;30(4):337-43.

133. McHorney CA, Ware JE Jr, Lu JF, Sherbourne CD. The MOS 36-item ShortForm Health Survey (SF-36): III. Tests of data quality, scaling assumptions, and reliability across diverse patient groups. Med Care. 1994;32(1):40-66.

134. Beusterien KM, Steinwald B, Ware JE Jr. Usefulness of the SF-36 Health Survey in measuring health outcomes in the depressed elderly. J Geriatr Psychiatry Neurol. 1996;9(1):13-21.

135. Kosinski M, Keller SD, Ware JE Jr, Hatoum HT, Kong SX. The SF-36 Health Survey as a generic outcome measure in clinical trials of patients with osteoarthritis and rheumatoid arthritis: relative validity of scales in relation to clinical measures of arthritis severity. Med Care. 1999;37(5 Suppl):MS23-39.

136. Chen K-M, Chen M-H, Lin M-H, Fan J-T, Lin H-S, Li C-H. Effects of yoga on sleep quality and depression in elders in assisted living facilities. J Nurs Res. 2010;18(1):53-61.

137. Sahajpal P, Ralte R. Impact of induced yogic relaxation training (IYRT) on stress-level, self-concept and quality of sleep among minority group individuals. J Indian Psychol. 2000;18(1-2):66-73.

138. Koenig HG, Westlund RE, George LK, Hughes DC, Blazer DG, Hybels C. Abbreviating the Duke Social Support Index for use in chronically ill elderly individuals. Psychosomatics. 1993;34(1):61-9.

139. Goodger B, Byles J, Higganbotham N, Mishra G. Assessment of a short scale to measure social support among older people. Aust N Z J Public Health. 1999;23(3):260-5. 
140. Washburn RA, Smith KW, Jette AM, Janney CA. The Physical Activity Scale for the Elderly (PASE): development and evaluation. J Clin Epidemiol. 1993: 46(2):153-62.

141. Goldstein MG, Pinto BM, Marcus BH, Lynn H, Jette AM, Rakowski W, McDermott S, DePue JD, Milan FB, Dube C, et al. Physician-based physical activity counseling for middle-aged and older adults: A randomized trial. Ann Behav Med. 1999;21(1):40-7.

142. Dinger MK, Oman RF, Taylor EL, Vesely SK, Able J. Stability and convergent validity of the Physical Activity Scale for the Elderly (PASE). J Sports Med Phys Fitness. 2004;44(2):186-92.

143. Devilly GJ, Borkovec TD. Psychometric properties of the credibility/ expectancy questionnaire. J Behav Ther Exp Psychiatry. 2000;31(2):73-86.

144. Smeets RJ, Beelen S, Goossens ME, Schouten EG, Knottnerus JA, Vlaeyen JW. Treatment expectancy and credibility are associated with the outcome of both physical and cognitive-behavioral treatment in chronic low back pain. Clin J Pain. 2008:24(4):305-15.

145. SAS Institute Inc. SAS: 9.2 Language Reference: Concepts. 2nd ed. Cary: SAS Institute Inc; 2010

146. Team RDC. R: a language and environment for statistical computing. Vienna: R Foundation for Statistical Computing; 2011.

147. Hertzog MA. Considerations in determining sample size for pilot studies. Res Nurs Health. 2008;31(2):191

148. McLachlan G, Krishnan T. The EM Algorithm and Extensions. 2nd ed. New Jersey: Wiley; 2008.

149. Tsiatis A. Semiparametric theory and missing data. New York: Springer; 2006.

150. Carpenter J, Kenward M. Multiple imputation and its application. Chichester: Wiley; 2013.

151. Nielsen S. Proper and improper multiple imputation. Int Stat Rev. 2003;71: 593-607.

152. Little R, Rubin D. Statistical analysis with missing data. 2nd ed. New Jersey: Wiley; 2002.

153. Molenberghs G, Kenward M. Missing data in clinical studies. Chichester: Wiley; 2008

Ready to submit your research? Choose BMC and benefit from:

- fast, convenient online submission

- thorough peer review by experienced researchers in your field

- rapid publication on acceptance

- support for research data, including large and complex data types

- gold Open Access which fosters wider collaboration and increased citations

- maximum visibility for your research: over $100 \mathrm{M}$ website views per year

At $\mathrm{BMC}$, research is always in progress.

Learn more biomedcentral.com/submissions 